\title{
Lumen
}

Selected Proceedings from the Canadian Society for Eighteenth-Century Studies

\section{Etait-ce la faute à Voltaire? Le Patriarche de Ferney devant le tribunal des intellectuels juifs}

\section{Léonard Rosmarin}

Volume 12, 1993

URI : https://id.erudit.org/iderudit/1012580ar

DOI : https://doi.org/10.7202/1012580ar

Aller au sommaire du numéro

Éditeur(s)

Canadian Society for Eighteenth-Century Studies / Société canadienne d'étude du dix-huitième siècle

ISSN

1209-3696 (imprimé)

1927-8284 (numérique)

Découvrir la revue

Citer cet article

Rosmarin, L. (1993). Etait-ce la faute à Voltaire? Le Patriarche de Ferney devant le tribunal des intellectuels juifs. Lumen, 12, 73-79.

https://doi.org/10.7202/1012580ar

Copyright (C Canadian Society for Eighteenth-Century Studies / Sociéte canadienne d'étude du dix-huitième siècle, 1993
Ce document est protégé par la loi sur le droit d'auteur. L'utilisation des services d'Érudit (y compris la reproduction) est assujettie à sa politique d'utilisation que vous pouvez consulter en ligne.

https://apropos.erudit.org/fr/usagers/politique-dutilisation/ 


\section{Etait-ce la faute à Voltaire? Le Patriarche de Ferney devant le tribunal des intellectuels juifs}

Plus de deux cents ans après sa mort, Voltaire continue à susciter de violentes controverses dans les milieux intellectuels juifs. La plupart d'entre eux l'abordent avec la prudence d'un expert en explosifs désamorçant une bombe. D'un côté, ils lui reconnaissent le mérite d'avoir lutté inlassablement pour le triomphe des droits de l'homme, triomphe qui aura fini par améliorer le sort de leurs coreligionnaires ailleurs aussi bien qu'en France. De l'autre, ils l'accusent presque, comme le savant Arthur Herzberg, d'avoir donné des lettres de noblesse à l'antisémitisme, d'en être, selon l'expression de Léon Poliakov, 'le saint patron.'

Il semble d'autant plus difficile de dédramatiser le débat que l'histoire juive, déjà lourde d'événements tragiques, fut marquée au cours de la Seconde Guerre mondiale par l'énormité de l'Holocauste. Pour nombre de Juifs, la blessure s'avère inguérissable. Ils demeurent en état d'alerte lors même qu'ils rappellent leurs rapports pré-1940 avec les non-Juifs. Ils voient partout les signes avant-coureurs de la tragédie qu'allait vivre leur peuple. Poliakov et Herzberg donnent comme preuve de l'influence malheureuse du patriarche de Ferney un livre publié à Paris en 1942c'est-à-dire, quand le pouvoir nazi était à son fort-Voltaire antijuif de Henri Labrousse. Cet agrégé d'histoire n'avait eu en effet aucune peine à composer, au fil des années, un volume de deux cent cinquante pages où il s'était répandu en invectives contre le peuple d'Israël.

Il est évident que des intellectuels juifs comme Poliakov et Herzberg, qui taxaient Voltaire d'antisémitisme dans les années 60, n'allaient pas souscrire au jugement nuancé et somme toute favorable que formula à son sujet un Israélite du 18e siècle, Zalkind Hourwitz:

Il se peut bien que Voltaire en ait moins voulu aux Juifs modernes qu'aux anciens, c'est-à-dire au tronc du christianisme contre lequel il vise sans cesse. Quoi qu'il en soit, les Juifs lui pardonnent tout mal qu'il leur a fait en faveur du bien qu'il leur a fait, quoique sans le vouloir, peut-être même sans le savoir; car 
s'ils jouissent depuis quelques années d'un peu de repos, ils en sont redevables au progrès des lumières, auquel Voltaire a sûrement plus contribué qu'aucun autre écrivain, par ses nombreux ouvrages contre le fanatisme. ${ }^{1}$

Il semble que ce contemporain de Voltaire ait été beaucoup plus proche de la vérité que certains de ses coreligionnaires du 20e siècle, hantés qu'ils restent par le cauchemar de la 'solution finale.' A comparer plus sobrement les méthodes de travail des savants juifs hostiles au philosophe et celles qu'avait adoptées l'antisémite Labrousse, on constate qu'ils ont tous tendance à commettre contre ses textes la même sorte de trahison, encore que pour des raisons diamétralement opposées. Ils arrachent les remarques anti-juives-ou du moins qui paraissent tellesà leur contexte d'ensemble. Ils extrapolent à partir de passages isolés. Labrousse se contente par exemple $d^{\prime}$ invoquer un nom illustre comme caution pour appuyer sa thèse d'une race tarée. Les intellectuels juifs, eux, font carrément assumer à l'apôtre de la tolérance sa part de responsabilité dans le développement de l'antisémitisme.

Pour comprendre le malaise juif, même chez des Poliakov et des Herzberg, ${ }^{2}$ une analyse des accusations portées contre Voltaire s'impose.

Les Juifs qui croient sincèrement à son antisémitisme lui reprochent de se fonder sur une lecture littérale de l'Ancien Testament pour les représenter sous une forme caricaturale. Ils l'accusent de les décrire comme des stéréotypes que ne désavoueraient pas leurs ennemis d'aujourd'hui. Ils aperçoivent en lui celui qui, le premier, a suggéré que les Israélites formaient, en raison de leur attachement à la foi de leurs ancêtres, une nation d'irrécupérables. Léon Poliakov cite un passage du Dictionnaire philosophique à l'en croire particulièrement révoltant:

...vous ne trouverez en eux qu'un peuple ignorant et barbare, qui joint depuis longtemps la plus sordide avarice à la plus détestable superstition et à la plus invincible haine pour tous les peuples qui les tolèrent et qui les enrichissent. Il ne faut pourtant pas les brûler. ${ }^{3}$

Poliakov voit dans cette dernière phrase une pirouette assez diabolique. Toutefois l'idée qui le révolte plus que toute autre, c'est celle que Voltaire émet sur l'esprit stérile des Israélites, leur incapacité à créer, partant leur infériorité par rapport aux peuples de l'Europe chrétienne. Il relève dans l'article 'Job' du Dictionnaire philosophique la remarque que les 'Juifs sont plagiaires en tout.' Il en souligne même une autre selon lui encore plus péjorative et qui est tirée du chapitre 7 de l'Essai sur les moeurs: 'On 
regardait les Juifs du même oeil que nous voyons les nègres, comme une espèce $d$ 'homme inférieur.'

Il n'est pas indifférent de noter que les érudits de foi israélite n'accablent pas Rousseau ni Montesquieu du même reproche anachronique d'antisémitisme. Ils voient en eux les champions des droits de la personne dont les Juifs ont pu se faire fort pour combattre le racisme. Rousseau ne cache pas en effet son admiration pour un peuple qui a pu-comme par miracle-conserver sa specificité culturelle à travers toutes les vicissitudes de son histoire tragique alors que d'autres nations, beaucoup plus puissantes en leur temps, $n$ 'avaient laissé que les vestiges d'une gloire passée. Montesquieu, quant à lui, sans éprouver pour eux la même sympathie, juge aberrant de haïr les Israélites simplement parce qu'ils vivent à la périphérie de la société et qu'ils exercent la profession honnie d'usuriers. Il suffirait à ses yeux de les accepter comme citoyens à part entière pour qu'ils cessent de se comporter en marginaux.

Il importe d'observer à la décharge de Voltaire qu'il a, à diverses reprises, tenu des arguments semblables pour expliquer la marginalité de ce peuple, et nous y reviendrons par la suite. Les attaques, cependant, qu'il dirige contre l'Ancien Testament, les Hébreux et leur Dieu jaloux sont d'une telle virulence que certains Juifs, meurtris dans leur chair, concluent chez lui à un mépris qui s'étendrait à tous leurs coreligionnaires, tant à ceux du 18e siècle et des époques futures qu'à ceux des temps bibliques.

La question toutefois demeure de savoir pourquoi certains textes bibliques révoltent l'apôtre des Lumières. La réponse semble bien résider dans la nature du code éthique qu'il applique aux histoires du Livre Saint. Il trouve notamment inacceptables les massacres commis par les Hébreux contre des populations qui ne leur avaient fait aucun tort. Dans cette catégorie de massacres se rangent aussi l'assaut donné à la ville de Sichem par Siméon et Lévi, l'extermination des Madianites dans le désert, la dévastation qui accompagnait la conquête de la Palestine du temps de Josué, et la destruction des Amalécites sous le règne de Saül. Comme Voltaire ne manque pas de le remarquer, tous ces massacres furent ordonnés par Dieu lui-même. Et c'est à Yahvé surtout que s'en prend l'auteur du Traité sur la tolérance. Voltaire l'accuse purement et simplement d'immoralité. Ce faisant, il se réfère aux épisodes de la Bible où le Seigneur venge les infidélités religieuses des Israélites. Le Dieu des Hébreux commanda aux Lévites de tuer tous les membres des tribus qui avaient vénéré le veau d'or, à l'exception d'Aaron, le plus coupable, qui non seulement évita le châtiment mais fut promu au rang de grand prêtre. Il infligea par surcroît toute une gamme de catastrophes à ceux qui avaient osé contester sa loi. D'où la fureur de Voltaire qui l'accuse d'avoir sanctionné ainsi les persécutions religieuses, 
déclenchées par les autorités séculaires, depuis Constantin jusqu'à la saint-Barthélemy. En d'autres termes, il ne pardonne pas au Dieu des Juifs d'avoir fait un enfer de la vie humaine.

Loin de 'décolérer' avec l'âge, Voltaire multipliait ses attaques contre un livre prétendu saint qui sanctionnait tant d'horreurs. Dans un article savant, Roland Mortier a étudié les ajouts successifs que l'écrivain apporta à un paragraphe du chapitre VII, 'Des Moeurs des Juifs,' de son Examen important de Milord Bolingbroke. ${ }^{4}$ Entre 1766, date de la parution de l'ouvrage, et 1776, époque des dernières modifications, le seul paragraphe porte en effet témoignage d'une véritable escalade de l'indignation. Voltaire s'y penche à trois reprises sur le comportement d'un peuple dit élu qui ne se gêne pas pour unir la sodomie au meurtre. Le ton va de la goguenardise écoeurée dans la version initiale à l'exaspération rageuse dans la version définitive. Mais il suffit de suivre la montée de la colère du philosophe pour comprendre qu'il vise moins les Israélites et leur Dieu croque-mitaine, approbateur de turpitudes, que l'église catholique de son temps et sa persistance à voir dans des histoires grotesques une révélation divine: 'Quel est l'homme de bien qui ne se sente ému de tant d'horreurs,' s'écrie-t-il. 'Et on les souffre! Que dis-je? On les adore! Que d'imbéciles, mais que de monstres!' Et c'est là précisément ce qui révolte Voltaire: une institution ecclésiastique, à l'époque des Lumières, chérissant comme des vérités absolues des mensonges aberrants et monstrueux. Ainsi, chaque fois qu'il se déchaîne contre le peuple de l'Ancien Testament, c'est, au fond, l'Infâme qu'il continue à pourfendre.

D'ailleurș, quand Voltaire prend l'église catholique avec ses doctrines comme cible de ses insolences, il lui assène des coups, pour le moins, aussi meurtriers que ceux dont il roue les Juifs. Jésus, inspirateur de la religion chrétienne? Un agitateur provenant de la lie du peuple-ce sont les paroles mêmes de l'auteur-non sans ressemblance avec l'anglais Fox, émeutier de canaille prêchant quelquefois une bonne morale. La Trinité? Sophisme qui insulte à l'intelligence, puisqu'elle consiste à soutenir que trois dieux n'en sont qu'un. L'incarnation et la transsubstantiation? Des fictions infantiles et débiles. Quelques années à peine avant sa mort, Voltaire écrit même avec rage et crûment:

On a poussé le blasphème jusqu'à faire un article de foi que Dieu est venu chier et pisser sur la terre, et que nous le mangeons après qu'il a été pendu; que nous le chions et que nous le pissons; et on dispute gravement si c'était la nature divine ou la nature humaine qui chiait ou qui pissait. (Mortier 24) 
Il est donc clair que Voltaire ne met pas le Juifs au pilori dans le dessein de valoriser ou d'angéliser les Chrétiens. Il malmène ces derniers avec une égale brutalité. En outre, l'intransigeance avec laquelle il juge le peuple hébreux et ceux qui croient littéralement à l'Ancien Testament ne l'aveugle pas sur la réalité de la vie israélite de son temps. Malgré les préjugés dont il ne se débarrassera jamais tout à fait, il s'évertue aussi à établir une distinction nette entre les tribus hébraïques et leurs descendants du 18e siècle. Il se garde de les envelopper dans une même réprobation. Sa réaction à la lettre d'Isaac Pinto, Juif d'origine portugaise, est révélatrice à cet égard. Pinto avait reproché à l'écrivain les remarques haineuses qu'il avait faites sur les Juifs dans le Dictionnaire philosohique. Le 21 juillet 1762, Voltaire lui répond avec bienveillance:

Les lignes dont vous vous plaignez, Monsieur, sont violentes et injustes. Il y a parmi vous des hommes très instruits et très respectables; votre lettre m'en convainc assez. J'aurai soin de faire un carton dans la nouvelle édition. Quand on a eu un tort, il faut le réparer; et j'ai eu tort d'attribuer à toute une nation les vices de plusieurs particuliers...Restez Juif, puisque vous l'êtes. Vous n'égorgerez point quarante-deux mille hommes pour n'avoir pas bien prononcé 'schibboleth,' ni vingt-quatre mille hommes pour avoir couché avec des Madianites. Mais soyez philosophe, c'est tout ce que je peux vous souhaiter de mieux dans cette courte vie. (Moland XLII: 181)

Or, exhorter les Israélites de son époque à devenir philosophes, c'est croire qu'ils ressemblent aux autres hommes et qu'il peuvent, comme eux, aspirer à la perfectibilité. C'est laisser entendre que certains comportements juifs et répréhensibles ne découlent pas d'une nature intrinsèquement tarée. Il suffirait, pour les 'récupérer,' de les intégrer à la société dominante au lieu'de les cantonner dans des ghettos. Avec perspicacité, Voltaire comprend avant Hegel que si certains Juifs ont un comportement financier qui peut paraître louche, c'est que les Gentils les y ont contraints. Cette explication d'ordre sociologique que l'auteur présente dans son Dictionnaire philosophique, fait ainsi échec à un des stéréotypes antisémites où des Juifs du $20 \mathrm{e}$ siècle croient découvrir une facette de la pensée voltairienne et ses retombées. Décrivant les persécutions auxquelles les Juifs d'Espagne furent en proie, l'injustice de leur condition de paria, de l'interdiction où ils étaient de posséder aucun bien-fond ou d'exercer aucune profession, il ajoute: 'Le commerce, profession longtemps méprisée par la plupart dees peuples de l’Europe fut leur unique ressource dans ces siècles barbares; et comme ils s'y enrichirent nécessairement, on les traita d'infâmes usuriers' (Moland XIX: 524-525). Cette seule remarque suffit à infirmer la thèse de Léon 
Poliakov. A l'en croire, Voltaire aurait dénoncé la cupidité, la sournoiserie et le cynisme des Juifs en affaires parce qu'il aurait inconsciemment cherché à exorciser le dégoût qu'il ressentait devant sa propre passion de l'argent (Poliakov 115).

Il n'en reste pas moins que les preuves qui peuvent être rassemblées pour défendre Voltaire contre l'accusation d'antisémitisme ne sauraient désarmer ses détracteurs. En premier lieu, Voltaire n'a jamais tenu la promesse qu'il avait faite à Isaac Pinto d'enlever les passages que son correspondant avait jugés offensants et injustes envers son peuple. En second lieu-et cet argument a sans doute beaucoup plus de poidsjamais l'apôtre des Lumières n'a rendu d'hommage public à des Juifs qui avaient admirablement incarné son idéal du philosophe. Assurément, Voltaire, on l'a vu, avait conjuré Pinto de le devenir. Mais ce dernier l'avait été depuis longtemps quand il reçut sa célèbre lettre, comme l'avaient été d'autres coreligionnaires tout aussi 'philosophes.'

Ce silence obstinément gardé sur des intellectuels comme Pinto et Zalkind Hourwitz entretient à propos des rapports de Voltaire avec ses contemporains israélites une ambiguité que les Juifs du 20e siècle ont peine à lever. Poliakov et Herzberg voient dans ce refus de saluer des esprits d'un mérite certain un préjugé indéracinable. Ils notent que le philosophe, si généreux à certains égards, n'a jamais pu dépasser l'équation 'foi religieuse=superstition.' Parce que quelques intellectuels du 18e siècle n'avaient pas hésité à se déclarer juifs, ils ne pouvaient, malgré leurs qualités incontestables, ressembler tout à fait aux autres aux yeux de Voltaire.

Cette équivoque qui semble bien planer sur l'attitude du philosophe envers les Juifs trahit les limites de l'esprit de tolérance qu'on a coutume d'associer aux Lumières. Certes, Voltaire a combattu inlassablement la bêtise, le fanatisme, la superstition et l'ignorance, sous quelque forme qu'ils lui apparussent. Assurément, il s'est cru éclairé, généreux, et souvent l'a été. Mais comme l'ont fait observer quelques critiques juifs, malgré une interprétation sujette à caution de son oeuvre, l'esprit philosophique voltairien donnait dans le conformisme. Il tendait davantage à exclure les différences qu'à les accueillir et visait à l'assimilation de l'autre. Il n'était toutefois pas le seul à réfléchir de la sorte. Un des champions de la cause juive au 18e siècle, l'abbé Grégoire, était persuadé par exemple qu'en leur octroyant la citoyenneté française, on leur ferait perdre au bout d'une génération leur spécificité culturelle et religieuse. Au vrai, la notion de la tolérance dont se vantaient, peut-être à tort, certains philosophes des Lumières, fait songer au vers du célèbre poème de Paul Valéry, 'Le Cimetière marin': 'Rendre la lumière suppose d'ombre la morne moitié.' 
A n'en point douter, la méfiance que nourrissait Voltaire envers ceux qui tiennent à sauvegarder leurs différences ne devait pas mener à la persécution. Ni la virulence de son antijudaïsme ne devait le pousser à vouloir 'brûler' les descendants du peuple de l'Ancien Testament. Mais, comme l'ont vu nombre d'intellectuels juifs de l'après-holocauste, au début des années 40 des racistes xénophobes, se réclamant d'un Voltaire grotesquement perverti et s'enorgueillissant de représenter l'esprit français dans toute sa pureté, n'allaient pas montrer les mêmes scrupules.

\section{LÉONARD ROSMARIN}

Brock University

\section{Notes}

1 Cité dans Léon Poliakov, Histoire de l'antisémitisme, t. 3, De Voltaire à Wagner (Paris: Calmann-Lévy, 1968) 117. Abrégé ci-après 'Poliakov.'

2 Arthur Hertzberg, The French Enlightenment and the Jews (New York: Columbia UP, 1968).

3 Voltaire, Oeuvres complètes, t.XIX, Dictionnaire philosophique, éd. L. Moland (Paris: Garnier Frères, 1877-1882) 518. Abrégé ci-après 'Moland.'

4 Roland Mortier, 'Voltaire et la Bible, ou les ruses du polémiste,' Colloque 76 Voltaire (London, ON: Dept. of French, U of Western Ontario, 1983) 19-27. Abrégé ci-après 'Mortier.' 